R. V. Salyutin

Coordinating Centre of Transplantation for Organs, Tissue and Cells, Ministry of Health of Ukraine, Kyiv, Ukraine

e-mail: r.salutin@mail.ru

\title{
CHANGE OF THE PATTERN OF MANAGEMENT OF THE KIDNEY TRANSPLANT PATIENTS WITH TERMINAL STAGE OF CHRONIC RENAL FAILURE
}

\section{ABSTRACT}

The review presents the results of clinical use of $m T O R$ inhibitors, Everolimus in particular, in the immunosuppressive therapy regimens. It has been established that immunosuppressive therapy regimens including mTOR inhibitors are preferred in patients with high and moderate risk of transplant loss. Analysis of the clinical use of $m T O R$ inhibitors has provided evidence of comparative frequency rate of wound complications and terms of surgical wound healing in the treatment with everolimus and routine therapy.

According to the data of clinical trials, minimization of calcineurin inhibitors therapy and switching to everolimus improves remote results of kidney transplantation both, owing to a reduced risk of nephrotoxic calcineurin inhibitors, anti-tumor and antiviral effects.

KEYWORDS: kidney transplantation, everolimus, mTOR inhibitor, immunosuppression

In recent decade the number of organ, including kidney, transplantations both from dead and living donor has noticeably increased. Kidney transplantation is the gold standard of treatment of the patients at thermal chronic renal insufficiency stage [2].

In view of increasing numbers of patients with transplanted kidney, it is a compelling task to protect kidney transplant from chronic damage (rejection) and thereby improve remote post-transplantation results by way of changing the paradigm of post-transplantation immune suppression (IS) [2, 3].

\section{MATERIALS AND METHODS}

In view of the above-said we put forward the following task: on the base of available research data and the results of the specialized symposia to substantiate the possibility of using $m T O R$ (mammalian target of rapamycin) as a component of strategy promoting improvement of separate results of kidney transplantation by protecting transplant from chronic rejection.

It is known that chronic rejection, proceeding against in the form of chronic transplantational nephropathy, interstitial necrosis and chronic allograft nephropathy / interstitial fibrosis and tubular atrophy (CAN/IFTA) and late transplant death are primarily determined by the autoimmune activity [2].
One of the main reasons of the development of transplant loss is the weakening of immunosuppression due to termination or minimization of therapy with calcineurin inhibitors in order to diminish their nephrotoxicity.

At present special attention has been paid to the use of mTOR inhibitor everolimus (Sertikan, Novartis) for creating safe effective immunosupression protocol with appropriate diminution of CNI exposition allowing improve remote results of kidney transplantation.

\section{RESULTS AND DISCUSSION}

The review presents the results of clinical use of $m T O R$ inhibitors, among them everolimus, in immunosuppressive therapy regimens. It has been established that immunosuppressive therapy regimens including $m T O R$ inhibitors are preferred in patients with high and moderate risk of graft loss.

The analysis of the clinical use of $m T O R$ inhibitors has provided evidence for comparative incidence rate of wound complications and terms of surgical wound healing in the treatment with everolimus and the routine therapy.

The results of the clinical trials have evidenced that minimization of therapy with calcineurin inhibitors and switching patients to everolimus allows for improvement of remote results of kidney transplantation both, 
at the expense of a reduced risk of nephrotoxic effect of calcineurin inhibitors, and owing to anti-tumor and antiviral effects.

The works of J.M. Campistol show a possibility of optimization of immunosuppression protocols by using mTOR inhibitors [1]. The results of 13 completed investigations enrolling 6,000 patients with kidney transplant treated with everolimus give evidences for equal effectiveness and safety of its clinical application in the case of $\mathrm{NCl}$ termination or minimization. It is noteworthy that $m T O R$ inhibitors similar to everolimus produced the significant pleiotropic (apart from immune suppressive) action like decrease of the cardiovascular diseases (CVD) and opportunistic virus infections. Also, an antitumor action of these drugs was noted $[1,8]$ that increases their value considerably.

The author notes the possibility and perspective for early administration of the mTOR inhibitors such as everolimus since they significantly decrease chronic rejection and increase the length of kidney transplant functioning. Further it is stressed that with the use of calcineurin inhibitors (CNIs) and mycophenolate mofetil (MPM) acute tear-off of the transplant occurs more rarely (in comparison with $m T O R$ inhibitors). However long-term overall survival of kidney allotransplant is not increased in view of developing CAN / IFTA and patient's death with functioning transplant

As has been found the morphological signs of CAN / IFTA (IFTA, atherosclerosis and glomerulosclerosis) in combination with clinical and laboratory parameters (increased creatinine level, arterial hypertension and proteinuria) were fixed in one-third cases of transplant death or rejection. Noteworthy, the main factors of a risk of CAN/IFTA development (importantly, resultant of CNI therapy) include an acute rejection during first post-transplantation year, late beginning of transplant functioning and virus infections.

Apart from this, the presence of cytomegalovirus infection is one of the triggering mechanisms in the CAN / IFTA development at the expense of specific inflammatory process and immune response enhancement, while the BK-virus mediated can be the cause of transplant death.

Besides, half of the transplant deaths in the CNIs-treated patients are conditioned by the recipient's death due to the primary malignant process or CVD developing post-transplantation.

The risk of CVD, caused by chronic renal insufficiency at pretransplantation period, grows in connection with CNI application that causes arteriole spasm and diabetes mellitus onset.

It has been found that CNI application increases the frequency of oncologic pathology onset during post-transplantation period, possibly, due to induction of DNA breaks and depression of the mechanisms of their reparation.

Thus, the high risk of development of CAN / IFTA, CVD and malignancies resulting from CNI intake presents serious substantiation of reduced length of CNI intake or refusal.

In the opinion of J.M. Campistol, the mTOR sirolimus and everolimus can in large measure resolve the problem of CNI negative action [1].

The earlier clinical investigations demonstrated that late transfer of patient with kidney transplant (6-12 months) from CNI onto sirolimus promoted improvement of kidney transplant functioning.

The author proposes that in order to minimize CNI nephrotoxicity, the patients with kidney transplant be switched earlier onto mTOR inhibitors thus reducing the risk of the appearance of kidney transplant dysfunctioning. Moreover, earlier switch onto mTOR inhibitors decreases the risk of development of CVD, virus infections and malignancies.

Positive characteristics of $m T O R$ inhibitors are primarily determined by the mechanism of their action, namely, inhibition of IL-2-stimulated T-cell proliferation. Apart from this, the $m T O R$ inhibitors block proliferation of hematopoietic and non-hematopoietic cells, including smooth muscle cells of vessels and bronchi, induced by growth factors, and depress p70S6 kinase activation that leads to blocking of the cell cycle during transition from phase $G$ to phase $S$.

The $m T O R$ inhibitors are metabolized involving CYP3A isoenzyme of cytochrome $P 450$ and serve the substrate for P-glycoproteins. Therefore, when administering everolimus in combination with cyclosporine $A$ drugs it essential to remember about increase and prolongation of its concentration in the blood serum (such interaction with tacrolimus is not seen)

No less important fact is that the period of half-elimination of $m T O R$ inhibitors, that is the half-life of everolimus vs. sirolimus is shorter (28 and 62 hours, respectively) and therefore injection of load dose for everolimus is not required; and the balancing state with its use is reached quicker [6].

$S$. Vitko and coauthors report additional data showing that everolimus better maintains transplant functioning prior to CAN / IFTA development or at its early stage. On the base of large clinical material the author concludes that early administration of everolimus decreases development of infections by cytomegalovirus and BK virus, malignancies and CVD.

Apart from this, the author suggests the strategy of management of adverse effects of the mTOR inhibitors, including proteinuria and dyslipoproteinemia, mentioning that $m T O R$ inhibitors more frequently enhance available proteinuria rather than cause its appearance.

In the cases of the mTOR inhibitors- mediated proteinuria, the angiotensin-converting enzyme inhibitors or blockers of angiotensin receptors can be effective while the statins are administered for dyslipoproteinemia elimination. Should their effect be insufficient, it is recommended that the dose of $m T O R$ inhibitors be reduced or $m T O R$ inhibitor be replaced for cyclosporine A or tacrolimus. Replacement of $\mathrm{CNI}$ for $m T O R$ inhibitors is not recommended at proteinuria of more than $800 \mathrm{mg} / \mathrm{dl}$.

The results of the randomized multicenter trials indicate the absence of differences in the terms of kidney transplant function appearance, post-operation wound healing and 3-month tolerance of $m T O R$ inhibitors preparations in the groups of patients administered $m T O R$ inhibitors both at early terms and at 4 weeks following transplantation. These and other research findings decrease clinicians' concern relative possible effects of everolimus on wound healing.

There are published data giving a detailed description of several high-quality clinical investigations dealing with the use of everolimus for minimization of cyclosporine A and tacrolimus application [6]. The authors present the convincing data showing that the everolimus therapy regimen with minimization of $\mathrm{CNI}$ is as effective as the standard CNI-based therapy regimen in evaluating survivorship of allotransplant recipients and even more effective in evaluating kidney functioning. The fact of the absence of any differences in post-operation wound healing with the use of everolimus and mycophenolate mofetil-based immunosuppression schemes, with no great risk of a transplant functioning has been proved.

Based on the results of the clinical investigations the authors think it necessary to use everolimus for improving remote results of kidney transplantation, for reducing nephrotoxicity within a framework of the CNI therapy minimization strategy as well as in patients with moderate or high risk of chronic transplant rejection [6].

$H$. Holdaas and coauthors describe the results of clinical investigations on early CNI withdrawal and subsequent administration of everolimus. The strategy of early CNI withdrawal envisages its primary application for the sake of ensuring effective immunosuppression immediately after kidney transplantation. This reduce a risk of acute rejection and subsequent CNI withdrawal for nephrotoxicity elimination [4]. In this study the patients were administered everolimus during first 6 months after transplantation with initial CNI therapy (early conversion). The patients were divides into three groups according to the dates of switching from CNI to everolimus: 7 weeks, 4.5 and 6 months post-transplantation. The results obtained in all groups indicated that CNI therapy everolimus was effective and safe, bringing about improved kidney transplant functioning that is explained, first of all, by lesser nephrotoxic action of $m T O R$ inhibitors. The authors compared the effectiveness of therapy minimization or drug withdrawal protocols with subsequent everolimus administration protocol. They also compared its safety in combination with very low doses of tacrolimus and the standard MMF therapy with tacrolimus (so-called standard 


\begin{tabular}{|c|c|c|c|c|}
\hline \multirow{2}{*}{ STUDY } & \multicolumn{2}{|c|}{ ACUTE REJECTION CONFIRMED BY BIOPSY, \% } & \multicolumn{2}{|c|}{ BLOOD CYCLOSPORINE A CONCENTRATION, NG/ML } \\
\hline & EVEROLIMUS & CONTROL & EVEROLIMUS & CONTROL \\
\hline B156 [5] & 8,6 & 28,3 & $69 \pm 28$ & $110 \pm 52$ \\
\hline B201 [6] & 23,2 & 24,0 & $144 \pm 64$ & $157 \pm 61$ \\
\hline B251 [7] & 19,2 & 24,0 & $135 \pm 103$ & $168 \pm 127$ \\
\hline $\mathrm{A} 2306^{*}[9]$ & 25,9 & НП & $81,7 \pm 28,0$ & НП \\
\hline $\mathrm{A} 2307^{\star}[9]$ & 13,7 & $\mathrm{HП}$ & $63,7 \pm 30,0$ & $\mathrm{H} \Pi$ \\
\hline
\end{tabular}

immunosupression U.S. FDA protocol). Compared were also the effects of late switching (after more than 12 months) from CNI onto everolimus on the CAN / IFTA development [4].

The results obtained indicate the expediency to use everolimus in various combinations and schemes as early CNI replacement therapy primarily for the sake of improving remote results of kidney transplantation and transplant protection against chronic rejection. The table presents the data obtained during treatment with everolimus in the dose $1.5 \mathrm{mg} 12$ months post-transplantation.
Considering a good prospect for the use of $m T O R$ inhibitors, there are plans to conduct multicenter clinical trials for studying efficacy, safety and tolerance of early replacement of CNI for everolimus therapy in the recipients aged over 65 years; everolimus prescribed immediately posttransplantation or after one month CNI therapy in the recipients aged over 60 years who received kidney transplant from elderly donor (> 60 years). Also, mentioning should be made of the investigation carried out by $H$. Holdaas and colleagues in which they analyzed the cardiovascular effects and risk factors during a prolonged treatment with everolimus and CNI [4].

\section{CONCLUSIONS}

IN VIEW OF THE GREAT NUMBER OF BASIC AND CLINICAL INVESTIGATIONS CARRIED OUT IN RECENT TIME, WE MAY OBSERVE A TENDENCY TO CHANGING IMMUNE SUPPRESSIVE THERAPY SCHEMES THAT IS DETERMIINED BY THE NEED OF IMPROVING LIFE QUALITY OF TRANSPLANT RECIPIENTS, IMPROVING TRANSPLANT FUNCTIONING AND ITS PROTECTION AGAINST CHRONIC REJECTION. THE WIDE USE OF THE $m$ TOR INHIBITORS IN IMMUNE SUPPRESSION THERAPY SCHEMES IS PERSPECTIVE AND SAFE, PROMOTING BOTH IMPROVEMENT OF KIDNEY TRANSPLANTATION OUTCOME AND PROLONGATION OF TRANSPLANT FUNCTIONING.

\section{REFERENCES}

1. Campistol JM. Minimizing the risk of posttransplant malignancy. Transplantation. 2009; 87(suppl. 8):19-22.

2. Campistol JM, Boletis IN, Dantal J, et al. Chronic allograft nephropathy - a clinical syndrome: early detection and the potential role of proliferation signal inhibitors. Clin. Transplant. 2009; 23(3):769-777.

3. Arias M, Serón D, Moreso F, et al. Chronic renal allograft damage: existing challenges. Transplantation. 2011; 91(9):4-25.

4. Holdaas $H$, Bentdal $O$, Pfeffer $P$, et al. Early, abrupt conversion of de novo renal transplant patients from cyclosporine to everolimus: results of a pilot study. Clin. Transplant. 2008; 22(3):366-371.

5. Nashan B, Curtis J, Ponticelli C, et al. Everolimus and reduced exposure cyclosporine in de novo renal-transplant recipients: a three-year phase II, randomized, multicenter, open-label study. Transplantation. 2004; 78(9):1332-1340.

6. Vitko S, Margreiter R, Weimar W, et al. Everolimus (Certican) 12-month safety and efficacy versus mycophenolatemofetil in de novo renal transplant recipients. Transplantation. 2004; 78(10):1532-1540.

7. Lorber MI, Mulgaonkar S, Butt KM, et al. Everolimus versus mycophenolate mofetil in the prevention of rejection in de novo renal transplant recipients: a 3-year randomized, multicenter, phase III study. Transplantation. 2005; 80(2):244-252.

8. Monaco AP. The role of $m T O R$ inhibitors in the management of posttransplant malignancy. Transplantation. 2009; 87(2):157-163.

9. Tedesco-Silva HJr, Vitko S, Pascual J, et al. 12-month safety and efficacy of Everolimus with reduced exposure cyclosporine in de novo renal transplant recipients. Transpl. Int. 2007; 20(1):26-27.

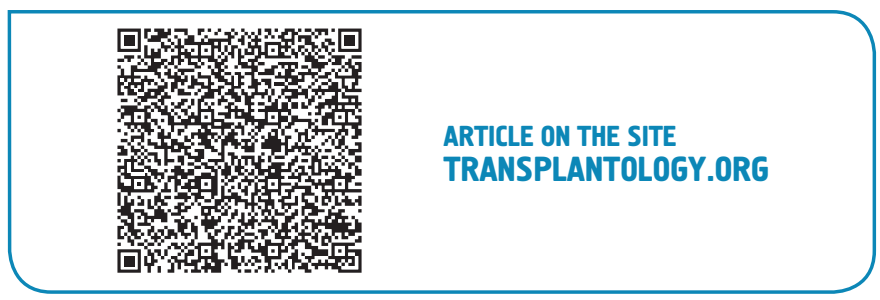

